\title{
TRATAMENTO CONSERVADOR DO TRAUMA ESPLÊNICO GRAU III
}

\author{
CONSERVATIVE TREATMENT OF SPLENIC TRAUMA GRADE III
}

Luana Hantequestt de Lima ${ }^{1 *}$, Emanoelle Aparecida Palangani ${ }^{1}$, Letícia Santos $\operatorname{Trad}^{1}$, João Pedro Zuin do Amaral ${ }^{2}$.

'UNINGÁ - Centro Universitário Ingá, Maringá, PR, Brasil.

${ }^{2}$ Hospital Angelina Caron, Campina Grande do Sul, PR, Brasil.

*lu_hant@outlook.com

\section{RESUMO}

O trauma abdominal é um dos mais prevalentes no contexto do politrauma. Devido ao seu potencial lesivo, está relacionado aos múltiplos quadros que elevam as taxas de morbidade e a mortalidade, assim, o trauma é a causa mais comum de morte em pessoas com menos de 45 anos de idade, representando mais de $10 \%$ das lesões traumáticas. Além disso, o baço é o órgão mais comumente lesado em traumas abdominais contusos, onde o trauma esplênico é o mecanismo de trauma que causa as lesões mais graves, sendo a lesão grau III a mais comum. $80 \%$ dos pacientes com lesão esplênica grau III, IV ou V descreveram apenas dor abdominal em seus prontuários e nestes casos pode ser aderido o tratamento conservador, o qual constitui o tratamento de escolha no trauma contuso em pacientes hemodinamicamente estáveis, na ausência de lesões de vísceras ocas. Este trabalho tem como objetivo enaltecer os benefícios do tratamento conservador em pacientes com trauma esplênico, estáveis e lúcidos, desde que haja uma boa condição hospitalar para atendê-los. Paciente chega ao hospital estável, orientado em tempo e espaço, com dor em região de face à esquerda, tórax à esquerda (durante a palpação de região de arcos costais, sem sinais hematomas ou de enfisema subcutâneo). Além disso, relata dor leve à palpação de região periumbilical à esquerda e não apresenta dor à palpação de coluna cervical, dorsal ou lombar. A ecografia mostrou líquido livre em cavidade, disperso, em grande quantidade, suspeitando de sangue na cavidade. Foi solicitada tomografia computadorizada de abdome que mostrou lesão esplênica grau III (AAST) e hematoma parenquimatoso contido, além de, presença de líquido livre peri-hepático em cavidade abdominal e baço heterogêneo com contornos irregulares e material hiperdenso de permeio, sugerindo hematoma capsular. Optou-se por um tratamento conservador, com tomografia de abdome e exames laboratoriais diários. Com isso, o paciente apresentou boa evolução e após 7 dias de internamento, realizou-se a alta hospitalar. O tratamento não-operatório de lesões esplênicas grau III, no trauma abdominal contuso, é uma opção segura desde que o hospital esteja adequadamente equipado e o paciente se encontre hemodinamicamente estável. É necessário que o hospital tenha uma equipe cirúrgica em tempo integral e recursos materiais, como ultrassonografia e tomografia computadorizada.

Palavras-chave: Conduta conservadora. Esplênica. Grau 3. Lesão. Tratamento. 